da Interculturalidade à Tecnologia

\title{
Design e resistência: bordados nos bastidores do Coletivo Linhas de Sampa
}

Fernanda do Nascimento Cintra é pesquisadora na área de design de moda com foco em bordados. Mestranda em Design no PPG Design da Universidade Anhembi Morumbi (UAM) e bolsista CAPES-PROSUP modalidade Taxa ${ }^{1}$.

<fernandancintra@gmail.com> ORCID: 0000-0003-3018-4413
Resumo Este artigo investiga aproximações entre fenômenos socioculturais que articulam design e resistência política, a partir do conceito de "ponto subversivo", de Rosziska Parker (2010). Nosso enfoque se dá nas ações realizadas pelo Coletivo paulistano Linhas de Sampa, em relação a alguns aspectos do contexto político do Brasil, nos últimos sete anos. A partir de uma abordagem sobre momentos pontuais da história do bordado e diferentes expressões de resistência, o trabalho do Coletivo é apresentado como exemplo da produção de diálogos entre design e política.

Palavras chave Design, resistência, bordados, Linhas de Sampa
10 presente trabalho foi realizado com apoio da Coordenação de Aperfeiçoamento de Pessoal de Nível Superior Brasil (CAPES) Código de Financiamento 001. 
da Interculturalidade

à Tecnologia

\section{Design and resistance: embroidery on the frames of Linhas de Sampa Collective}

Abstract This article investigates approximations between socio-cultural phenomena that articulate design and political resistance, based on the concept of "subversive stitch", by Rosziska Parker (2010). Our focus is on the actions carried out by the São Paulo Collective Linhas de Sampa, in relation to some aspects of the political context of Brazil, in the last seven years. From an approach to specific moments in the history of embroidery and different expressions of resistance, the work of the Collective is presented as an example of the production of dialogues between design and politics.

Keywords Design, resistance, embroidery, Linhas de Sampa

\section{Diseño y resistencia: bordado en los bastidores del Colectivo Linhas de Sampa}

peuta no Instituto Sedes Sapientiae (SP).

Mestre e Doutora em Psicologia pelo Núcleo de Estudos da Subjetividade (PUC-SP). Pós-Doutorado no Departamento de Artes da Goldsmiths University of London (UK). Professora do PPG Design da Universidade Anhembi Morumbi.

<cfmesquita@anhembi.br >

ORCID: 0000-0001-6860-0676
Resumen Este artículo investiga aproximaciones entre fenómenos socioculturales que articulan diseño y resistencia política, basados en el concepto de "punto subversivo", por Rosziska Parker (2010). Nos centramos en las acciones llevadas a cabo por el Colectivo de São Paulo Linhas de Sampa, en relación con algunos aspectos del contexto político de Brasil, en los últimos siete años. Desde una aproximación a momentos específicos en la historia del bordado y diferentes expresiones de resistencia, el trabajo del Colectivo se presenta como un ejemplo de la producción de diálogos entre diseño y política.

Palabras clave Diseño, resistencia, bordado, Linhas de Sampa 


\section{Introdução}

Manifestações no campo do design como roupas e artefatos, assim como técnicas manuais como desenhos e bordados, quando situadas em desalinho com os poderes vigentes podem resistir politicamente de diferentes maneiras: por exemplo, ao questionar os sistemas autoritários; ao combater a repressão da liberdade de expressão; ao conectar-se com o combate às formas opressoras de regulação da vida, entre outras práticas, ao longo da história e em diferentes lugares. $O$ design nesses casos, aparece empregado em sentido amplo e expandido. Por vezes, ao design é atribuído o adjetivo "politizado", pois, embora este campo conceitual teórico e prático seja sempre político em perspectivas éticas e estéticas, em determinadas situações, ações e produções, tornam-se explícitas as pautas relativas aos sistemas governamentais e ao Estado.

Este artigo integra uma pesquisa de Mestrado ${ }^{1} \mathrm{em}$ desenvolvimento. $O$ recorte aqui enfocado busca investigar aproximações entre fenômenos socioculturais que articulam design e resistência política, a partir do conceito de "ponto subversivo" de Rosziska Parker (2010) com um olhar para as práticas de bordados realizadas pelo Coletivo paulistano Linhas de Sampa, em relação a alguns aspectos do contexto político do Brasil dos últimos sete anos.

Ao longo das últimas três décadas, o mundo vem enfrentando crises globais. Alguns países mais que outros, vem reproduzindo aspectos dessas crises. No ano de 2008, ocorreu o colapso do sistema financeiro norte-americano $^{2}$ que desencadeou o movimento social Occupy Wall Street em 2011: um largo protesto contra a desigualdade social e econômica e o setor financeiro. Desde então, é possível observar que as milhares de pessoas que foram às ruas se manifestar naquela ocasião, iniciaram um movimento expressivo de encontros, ocupações e diversas formas de contestação que vem perdurando até os dias de hoje e nos mais diferentes lugares do mundo. São vários os exemplos que podem ser encontrados como reação ao crescimento do conservadorismo e do autoritarismo ${ }^{3}$, tais como os levantes sociais que despontaram com a Primavera Árabe, naquele mesmo ano.

Os eventos em torno da crise econômica norte-americana e da Primavera Árabe podem ser considerados como um dos principais impulsionadores de protestos em todo o mundo, que chegaram inclusive na China, no ano de 2011 e em Hong Kong, em 2014 ${ }^{4}$. As formas de luta que emergiram destes movimentos tinham muito em comum, tal como sintetiza Pinheiro-Machado: "foi forjada na rua uma nova geração, que busca, na atuação microscópica e na ação direta, o afeto radical, a criatividade política e a horizontalidade" (PINHEIRO-MACHADO, 2019, p. 18). 
No Brasil, um ciclo de reivindicações começa a ocorrer em 2013, a partir de pautas difusas, numa manifestação que reúne reivindicações ligadas, por exemplo, ao aumento das tarifas de transporte, à corrupção e aos custos do governo com a realização da Copa do Mundo no País. Estas manifestações seguem num crescente e, desde então, é possível notar que os levantes de 2013 deixaram marcas: crescimento do número de coletivos descentralizados e uma relevante ampliação de ativismos ligados aos movimentos feministas, LGBTQI+s e antirracistas, especialmente visíveis nas novas gerações. Nas ruas e avenidas das principais cidades do País, é possível perceber novas formas de organização, de luta, de afeto e de solidariedade social.

Deste mesmo fluxo, surgem inúmeros movimentos culturais que problematizam, questionam e expressam aspectos da situação social e política no País ${ }^{5}$. Entre eles está o Coletivo urbano chamado Linhas do Horizonte, nascido na cidade de Belo Horizonte (MG), um grupo de pessoas que se reúne em espaços públicos para usar linhas e agulhas como forma de resistência, bordando panfletos e faixas com desenhos e frases alinhados com pautas políticas, sociais e culturais, relativas ao contexto atual. De acordo com o manifesto do Coletivo, relatado em sua página do Facebook:

O Linhas do Horizonte é um grupo de resistência, que através do bordado e de outras formas de manifestação artística borda contra toda forma de violência aos direitos humanos, políticos e ambientais: homofobia, racismo, intolerância religiosa, censura, feminicídios e genocídios, etc (LINHAS DO HORIZONTE, 2017).

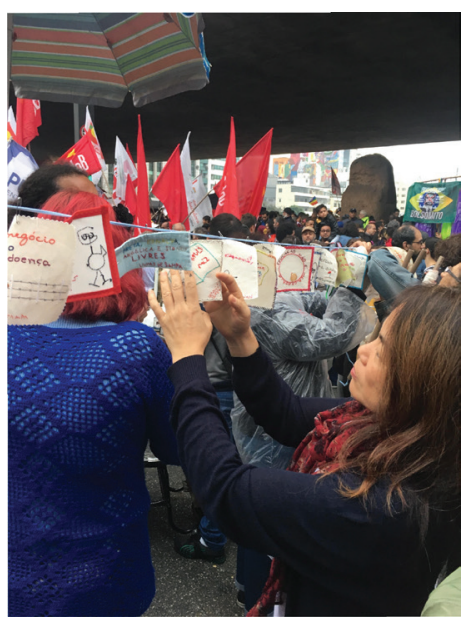

Fig 1. Tsunami pela Educação, agosto de 2019, São Paulo

Fonte: Imagem acervo Fernanda Cintra, 2019
A partir das ações deste grupo, surgiram outros e, entre eles, encontra-se o Coletivo Linhas de Sampa, que é formado por pessoas que bordam em tecidos palavras e desenhos, nas ruas da cidade de São Paulo (SP), defendendo bandeiras que fazem denúncias, questionam e problematizam determinadas causas sociais, opõem-se aos preconceitos e colocam-se a favor dos direitos humanos e políticos das minorias. Seus trabalhos são também conhecidos como "panfletos bordados" (LINHAS DE SAMPA, 2018). Este artigo pretende observar as ações do Coletivo e os modos de distribuição de seus panfletos (figura 1). Depois de delinear o contexto das manifestações brasileiras nos últimos anos (SOUZA, 2016; PINHEIRO-MACHADO, 2019) e de percorrer brevemente uma história do bordado (PARKER, 2010; BRATICH E BUSH, 2011; BORGES, 2019; BARBOSA RAMOS e PRADO, 2019), alinhado às manifestações de resistência, enfocaremos o Linhas de Sampa para refletir sobre suas ações, no sentido de realçar articulações entre design e política. 


\section{Nos bastidores da política brasileira: alguns momentos pontuais}

Os levantes populares do movimento Occupy Wall Street, da Primavera Árabe e tantos outros, ocorreram quase que simultaneamente ao redor do mundo. Imagens dos protestos circulavam de maneira ampla, em decorrência do poder de difusão da internet e das plataformas de mídias sociais. Com isso, inaugurou-se uma nova era, quando os objetivos de trabalhar por uma causa e exercer militância se ressignificaram, tendo como ferramenta principal os recursos de conectividade da rede mundial de computadores. É o chamado ativismo on-line. Felice et. al. colaboram:

Todas essas experiências, diversas em seus contextos culturais e políticos originaram-se on-line, em blogs, sites ou redes temáticas que, de forma autônoma disseminaram suas reivindicações, seus protestos, alcançando em breve tempo proporções que, em muitos casos superaram as fronteiras nacionais (FELICE et. al, 2017, p. 57).

A onda de protestos mundiais reverberou no Brasil, com a ocorrência de grandes manifestações, no ano de 2013. Esta conjuntura vinha formando-se há alguns anos. O período militar havia terminado no ano de 1985 e, via de regra, havia ocorrido o retorno à liberdade de expressão e aos modelos democráticos de eleição de governantes. Apesar desta retomada, nos anos seguintes ao término do regime autoritário, é possível entender que o País continuou sendo liderado por partidos que visavam lucros apenas para a elite, não incentivavam a inclusão social e efetuavam inúmeras privatizações, contexto que abriu espaço para o surgimento de partidos políticos emergentes, em especial aqueles faziam trabalho de base e cresciam em periferias ou em meio à classe trabalhadora (SOUZA, 2016).

No Brasil, "as maiores marchas da história", contaram com cerca de 13 milhões de pessoas de pessoas, que ocuparam as ruas em 130 cidades (MELO e VAZ, 2018) e são consideradas como um desdobramento das lutas da virada do século XX, ocorridas no mundo todo. Num primeiro momento, os movimentos se configuraram de forma "apartidária". Suas pautas reivindicavam melhorias nos sistemas de transporte público e em outros serviços oferecidos pelo governo, como saúde e educação. Além disso, se posicionavam contra os abusos corporativos em função da Copa do Mundo que ocorreria no ano seguinte.

Com as estratégias de comunicação ampliadas da internet e das redes sociais e sob o lema Não são só 20 centavos - valor do aumento das tarifas de transporte - as "Jornadas de Junho", como ficaram conhecidos estes levantes, levaram milhões de pessoas as ruas de centenas de cidades brasileiras de diferentes estados (MELO e VAZ, 2018). Na chamada "grande mídia" o fenômeno do "apartidarismo", foi, por muitas vezes, distorcido e disseminado como um evento que pregava o "antipartidarismo" - o que poderia ser facilmente entendido como crítica ao governo vigente. Destas 
manifestações, é possível entender que as pautas iniciais difusas foram esvaziadas e a maioria das reivindicações logo foram apropriadas pelas elites, para criticar as políticas do governo em exercício (PINHEIRO-MACHADO, 2019). Entretanto, apesar das distorções compreende-se que os atos reverberaram amplamente, no sentido de abrir um campo fértil de ação para várias formas de ativismo e de militância, em prol das mais diversas causas. Desde então, as Jornadas de Junho estimularam mais e mais pessoas a se organizar, ocupar espaços públicos e manifestar-se por meio de diferentes linguagens e aparatos.

No ano de 2014, os principais protestos enfocavam os investimentos na realização da Copa do Mundo. Os eventos ficaram conhecidos como Não vai ter Copa. Manifestantes atuavam contra o torneio nas redes sociais e expressavam denúncias nas ruas das principais capitais do País, denunciando a violência do Estado contra as populações mais vulneráveis e os acordos e licitações superfaturados de obras que não teriam função quando o evento terminasse. Alegavam especialmente que os campos da saúde e educação estavam em crise, necessitando de investimentos (PINHEIRO-MACHADO, 2019).

Em 2015, novos atos emergiram, desta vez, relacionados com lutas feministas, motivadas por uma sucessão de fatos. O Coletivo feminista Think Olga lançou uma campanha chamada \#PrimeiroAssédio, que convidava mulheres a relatar seus casos de assédio por meio da rede social Twitter. Esta ação teve enorme impacto, rendendo mais de 82.000 mensagens. Outros fatores, como um projeto de lei que dificultava a realização de aborto para vítimas de estupro, fizeram com que diversos coletivos feministas se articulassem para organizar protestos levando centenas de mulheres às ruas das principais capitais (ROSSI, 2015).

Naquele mesmo ano, ocorre o rompimento de uma barragem de dejetos provenientes da mineração realizada pela empresa Samarco. 0 fato envolveu o despejo de 39 milhões de metros cúbicos de rejeitos de minério de ferro que poluíram a bacia do Rio Doce e ocasionou 19 mortes, na cidade de Mariana (MG). Este acontecimento criou um circuito de manifestações em diferentes regiões do Brasil, majoritariamente denominadas como Não foi acidente (BOECKEL, 2015).

No ano de 2016, brasileiros foram às ruas pedir o fim da corrupção. Nesta ocasião, as demandas eram polarizadas, pois se conectavam a posicionamentos contra e a favor ao processo de impeachment da Presidenta Dilma Roussef (1947 -), em curso naquele momento. Intituladas de \#nãovaitergolpe e \#ForaDilma, ocorreram simultaneamente em mais de 300 cidades do País ${ }^{8}$ e culminaram na cassação do mandato presidencial, no mês de agosto daquele ano (PINHEIRO-MACHADO E SCALCO, p. 7). Na sequência, as medidas adotadas pelo presidente empossado Michel Temer (1940 -) seguiram produzindo desemprego e quedas econômicas (FERNANDES JR, 2019), fatores que levaram a novas reivindicações em todas as regiões do Brasil com o lema \#ForaTemer (RUFFATO, 2016). Tais protestos atravessaram o ano de 2016 e continuaram ocorrendo no ano de 2017, com foco contra as reformas trabalhistas propostas pelo governo, entre elas aquelas que incluíam a retirada de direitos dos trabalhadores. 
No ano de 2018, o assassinato da vereadora carioca Marielle Franco (1979-2018) em 14 de março resultou em inúmeros levantes nacionais e internacionais, que reverberavam a pergunta Quem matou Marielle Franco?. A socióloga lutava pelos direitos humanos e contra a violência nas favelas do Rio de Janeiro (ABRANTES, 2018), de modo que o ocorrido desencadeou o fortalecimento de vários grupos e reivindicações contra a violência policial nas periferias das grandes cidades (Portal G1, 2018). Neste mesmo ano, consolida-se a prisão do ex-presidente Luís Inácio Lula da Silva', fruto de um processo que caminhava desde as investigações ligadas à Petrobras, empreendidas pela chamada Operação Lava Jato, da Polícia Federal (EL PAÍS, 2018). Inúmeras manifestações contra a prisão levaram às ruas e às redes a frase \#LulaLivre (BALLOUSSIER, 2018).

Um outro grande movimento de 2018 foi intitulado \#Elenão, ato convocado por mulheres e com reverberação internacional, contra a candidatura do ex-deputado Jair Bolsonaro ${ }^{10}$ à presidência da República. As manifestações ocorreram em diversas regiões, envolvendo mais de 100 cidades e 50 países, no dia 29 de setembro (CARNEIRO ET AL, 2018).

Em 2019, diversos eventos nas ruas seguiram com múltiplas pautas: ambientais, raciais, em favor da educação, contra as políticas e ações do governo vigente, em diferentes áreas. É possível elencar atos relativos a questões ambientais, entre eles, o novo rompimento de barragem de dejetos, decorrente da mineração praticada pela empresa Vale do Rio Doce em Brumadinho (MG), desta vez com 270 mortos e destruição avassaladora da região (FELLET e SOUZA, 2019) e os incêndios ocorridos na região amazônica, que desencadearam mais de 2 mil kilômetros quadrados de áreas desmatadas (BARBOSA, 2019). Protestos em favor dos povos indígenas foram realizados em várias cidades no Brasil e do mundo (WATSON, 2019), estendendo-se ao longo de todo o ano, com os assassinatos dos caciques Emyra Wajãpi, no Amapá em Julho (ANDRADE, 2019); e Paulo Guajajara no Maranhão, em Novembro (PORTAL G1, 2019).

Outros atos ocorridos durante o ano de 2019 são disparados por ações contra o racismo. Entre eles destaca-se os 21 Dias de Ativismo Contra o Racismo!, ato criado pela Organização das Nações Unidas (PORTAL MÍDIA NINJA, 2019). As reivindicações em favor da educação e contra cortes de verbas, denominadas Tsunami pela Educação, também foram expressivas e ocorreram em mais de 85 cidades (PORTAL G1, 2019). Os protestos também continuaram contra as intervenções policiais violentas. Em uma destas, no mês de Abril no bairro Guadalupe (RJ), foram disparados mais de 80 tiros sobre o carro de uma família, matando o cantor Evaldo dos Santos Rosa, de 51 anos e o catador Luciano Macedo, de 27 anos; a outra teve como resultado o assassinato da menina Ágatha Félix, de 8 anos, no Complexo de favelas do Alemão (RJ), em Setembro (PORTAL G1, 2019).

É importante ressaltar que, muitas vezes, tais manifestações reclamam simultaneamente por pautas diversas. Os fatores anteriormente descritos desencadearam o surgimento de movimentos sociais e culturais que questionam a situação atual no País. Entre eles, encontram-se os panfletos 
bordados pelo Coletivo Linhas de Sampa, que no cenário dos últimos dois anos, articulam design, bordado e política. Para introduzir as práticas e técnicas utilizadas pelo grupo, é necessário compreender certas particularidades do campo do bordado, assunto que será tratado no próximo tópico.

\section{Bordado e resistência: o ponto subversivo}

Este tópico apresenta um breve percurso pela história do bordado, a partir do entendimento dessa prática tão antiga e popular. Para tanto, a obra da historiadora britânica Rozsiska Parker, The Subversive Stitch (2010) (O Ponto Subversivo, tradução nossa), é importante fonte historiográfica sobre o tema, pois considera o bordado como uma "prática subversiva", entre outras funções. Segundo Parker (2010), o bordado é conhecido como uma prática para ornamentar tecidos, fazendo uso da agulha, podendo ser feito com linhas ou contas variadas, criando desenhos, texturas, e adornos que permitem infinitas possibilidades de composição. Ganderton (2015) colabora, lembrando que:

Bordado pode ser definido a princípio, como a ornamentação em tecidos com pontos decorativos. É uma prática antiga, que engloba uma riqueza histórica e geográfica, pois os mesmos pontos são encontrados em trabalhos de várias partes do mundo ${ }^{11}$ (GANDERTON, 2015, p. 6, tradução nossa).

o bordado é uma prática composta por diferentes materiais, ferramentas e técnicas. Dentre os materiais, a principal matéria-prima são tecidos, base para receber o trabalho; e linhas, que dão forma, cor e vida aos bordados. As ferramentas utilizadas são diversas, entre elas estão tesouras, agulhas, alfinetes, marcadores de tecido, desmanchadores de pontos, dedais e bastidores. As técnicas utilizadas podem ser as mais variadas, e são elas que formam os inúmeros tipos de pontos e desenhos (IBID, 2015).

Inexiste registro preciso da data de execução do primeiro bordado: "As fontes são dispersas e escassas, assim como os relatos não passam de pontos fragmentados [...] muito do que ocorreu continua esperando revelação" (MALERONKA, 2007, p. 15). Para Parker (2010), o período do Renascimento ${ }^{12}$ foi delimitador, no sentido de separar os afazeres por gênero. A figura 2 mostra uma ilustração italiana do século XIV, que representa homens trabalhando como bordadeiros. Ao lado, apresenta mulheres na função de bordadeiras. A partir de então, o bordado passa a ser considerado uma atividade exclusivamente destinada às mulheres e ligada às boas

Fig 2. Homens bordando no séc. XIV e Mulheres bordando pós-renascimento, 1527 | Fonte: Parker (2010, p. 48 p. 62) maneiras, tal como costurar e cozinhar, práticas ensinadas nas esferas domésticas, de mãe para filha. 
O século XX também evidencia a prática do bordado como exclusividade feminina, fato que pode ser percebido a partir de escolas que incluíam a prática no treinamento de fazeres manuais, dedicados às mulheres: "[...] enquanto os garotos ganhavam livros, as garotas recebiam agulhas e linhas" (PARKER, 2010, p. 193). Após a Segunda Guerra Mundial, as práticas domésticas são novamente incorporadas às revistas femininas, por meio de encartes de modelos para bordar, com a proposta de resgatar conceitos como paz, prosperidade, e abundância, por meio desta atividade que ficara em suspenso durante os anos de batalha (IBID, p. 202).

Neste artigo, é importante destacar alguns exemplos nos quais o bordado e resistência política encontram-se de maneiras expressivas. Entre eles, são dignos de nota os banners bordados do Movimento Sufragista; os bordados pela liberação feminina, a partir da década de 1960; e as práticas de bordado empregadas pela designer de moda Zuzu Angel, no contexto da ditadura civil-militar brasileira. Para melhor compreender e estabelecer estas relações, conectadas ao contexto da produção de bordados, nos utilizaremos do conceito de "ponto subversivo", proposto por Parker (2010):

[...] o bordado, é sem dúvida uma prática cultural que envolve iconografia, estilo e função social [...] bordadeiros transformam materiais para produzir sentido - e toda uma gama de significados - são invariavelmente notados [...] (PARKER, 2010, p. 6, tradução nossa ${ }^{13}$ ).

Tendo início na Inglaterra a partir da segunda metade do século XVIII e durante todo o século XIX, a Revolução Industrial consolida o surgimento da indústria como modo majoritário de produção e pela formação do Capitalismo (MORAES, 2017). Ao final do século XIX, em decorrência da industrialização, a inserção das mulheres na vida social e no trabalho se amplia. Atuando nessas instâncias, nas quais até então elas haviam sido silenciadas, emergem manifestações de descontentamento com relação às injustiças de gênero, tais como o direito de receber educação universitária, de exercer a medicina, de ter propriedades em seu nome, entre tantos outros. Algumas dessas manifestações são realizadas por meio de banners bordados (PARKER, 2010).

Para que a proposta triunfasse, primeiramente as mulheres reivindicavam pelo direito civil e político ao voto (LLOYD, 1968). O movimento insurgente das "sufragistas" - como eram chamadas - defendia a extensão do direito de voto sem distinção de gênero, etnia, origem ou classe social (PINTO, 2010). As primeiras manifestações surgiram no final do século XIX, na Inglaterra, espalhando-se por alguns outros países industrializados e perdurando até o início do século XX. Inspiradas nos protestos sindicais com greves e paralisações, onde eram usados banners impressos e bandeiras sindicais, as feministas produziam materiais expressivos, diferenciando-se graças a habilidade das mulheres com atividades manuais, eclesiásticas, costuras e, principalmente, bordados (IBID, p. 198). 


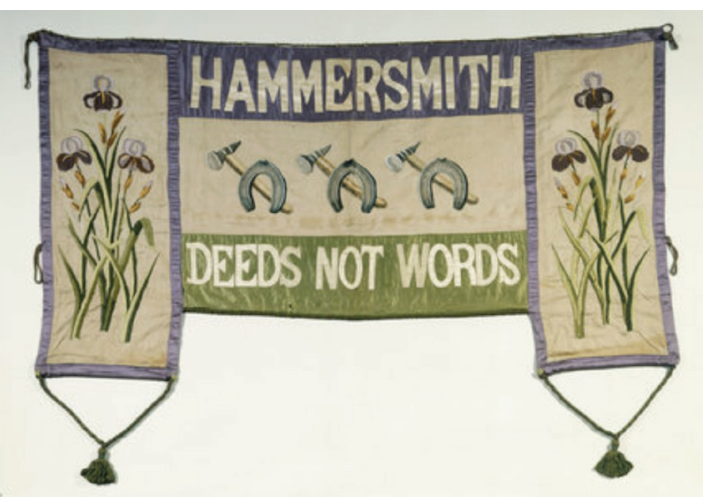

Fig 3. Banner Sufragista, 1907

Fonte: Acervo Museu de Londres

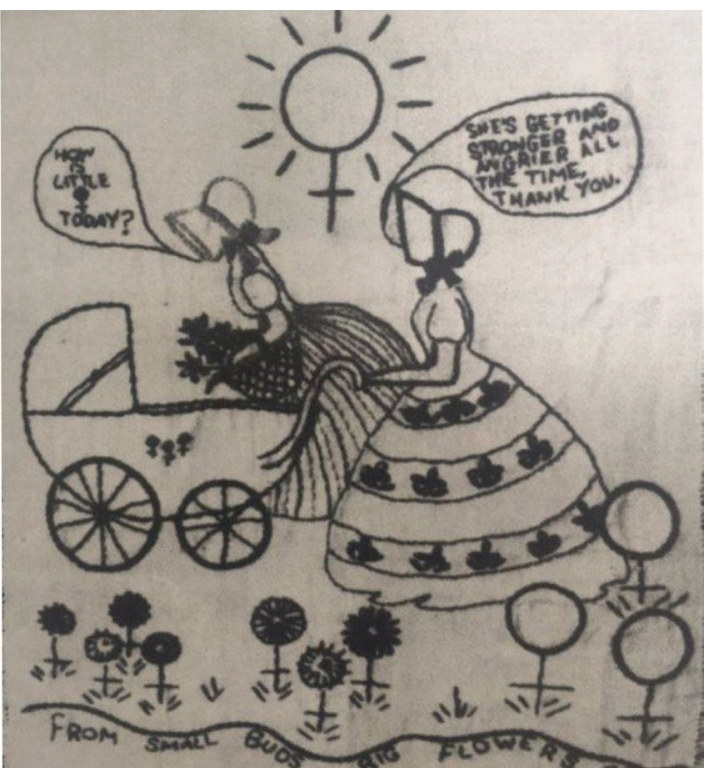

Fig 4. Bordado da Segunda Onda

Feminista, 1970

Fonte: Parker (2010, p. 205)
Estas mulheres usavam o bordado para provocar questionamentos sobre o papel feminino na sociedade (PARKER, 2010). o banner sufragista da figura 3 é um bordado do ano de 1907, nas cores oficiais do movimento roxo e verde - e exibe a frase "atos e não palavras" (tradução nossa), com apliques de veludo e delicadas flores de íris, contrastando com a pintura do martelo e da ferradura, que são ferramentas normalmente ligadas à masculinidade. Este conjunto pode ser entendido como uma reivindicação de igualdade entre homens e mulheres.

Outro exemplo no qual é possível notar a relação entre a produção de bordados e contexto sócio-político é o movimento feminista ocorrido na década de 1970, também conhecido como "Segunda Onda Feminista". O período entre as duas guerras ficou marcado pela decadência dos movimentos feministas, que naquele período, graças à algumas conquistas, fez com que uma maioria de mulheres abandonasse qualquer tipo de militância. Nos Estados Unidos, por exemplo, depois de terem sido inseridas no espaço público e profissional, grande parte das mulheres foram demitidas, deixando seus postos de trabalho aos homens que voltavam da guerra, enquanto eram incentivadas a uma vida prioritariamente doméstica (GARCIA, 2018). As mulheres da Segunda Onda Feminista bordam de maneira subversiva, criticando os valores predominantes na sociedade pós-guerra. Seus bordados incentivam as mulheres a desenvolver seu poder pessoal, bem como uma voz de resistência. Alguns bordados desse período fazem uso de elementos do século XVIII, como apresenta o exemplo na figura 4, que combina a submissão feminina das mulheres Vitorianas ${ }^{14}$, com símbolos feministas e mensagens encorajadoras ${ }^{15}$.

No Brasil, um exemplo da técnica de bordados com caráter insurgente foi realizado pela designer de moda mineira Zuleika de Souza Netto (1921-1976), conhecida como Zuzu Angel, no contexto da ditadura civil-militar brasileira (1964-1985). Os acontecimentos da política influenciaram diretamente suas atividades como designer de moda, manifestando sua busca por respostas ao desaparecimento de seu filho Stuart Angel (1946-1971) no ano de 1971. O trabalho produzido por Angel é elaborado a partir de técnicas concentradas em bordados manuais de ponto cheio em estilo naif ${ }^{16}$, com formas ingênuas que não seguem padrões e que possuem traços coloridos que imitam cadernos infantis, como pode ser visto na figura 5 , com texturas, cores e relevos. Fazem alusão à prisão, à tortura e ao silenciamento, sofridos por Stuart ${ }^{17}$.

Para Borges (2019), as técnicas manuais como os bordados, entre outras práticas, podem ser consideradas capazes de produzir narrativas sobre a cultura popular. Por vezes, são consideradas menos valorosas, quando comparadas equivocadamente com a "alta cultura". Em suas próprias palavras: "As narrativas construídas sobre a chamada cultura popular são, muitas vezes, assimiladas em campos de oposição em relação a uma pretensa cultura erudita" (BORGES, 2019, p. 7). Tais práticas populares engendram saberes ancestrais, partindo de comunidades indígenas do Brasil e são potencializadas por outras culturas, quando realizadas por africanos e outros imigrantes, que forçosamente ou não, seguiram aportando no País: 


\begin{abstract}
Os registros históricos da presença e resistência desses povos permanecem no fazer intelectual e manual da cultura do nosso País [...] as linhas e as tramas são símbolos que costuram e afirmam sociabilidades, reforçando os sentimentos de pertença e de identidade cultural, possibilitando a transmissão de técnicas em momentos de partilha de valores e afetos [...] remetendo à ancestralidade e à permanência das tradições, somadas às transformações próprias do tempo e das gerações (BORGES, 2019, p. 7).
\end{abstract}

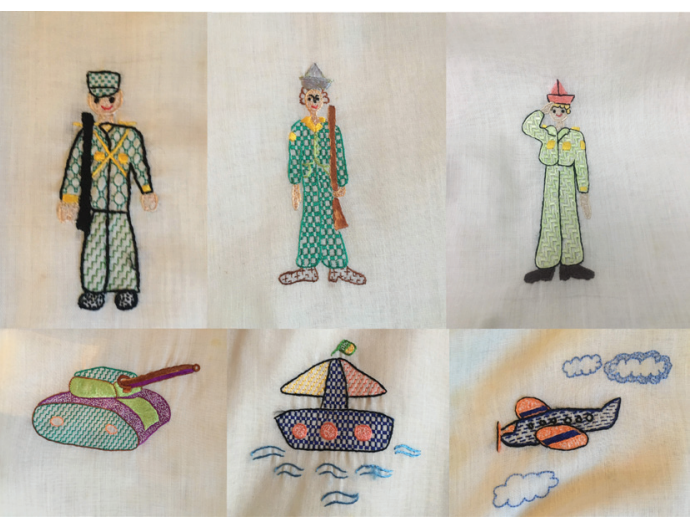

Fig 5. Detalhes dos bordados do vestido túnica

Fonte: Acervo documental do Instituto Zuzu Angel, 1971
As práticas manuais podem ser agentes de mudanças e de resistência, tanto econômicas como sociais ou culturais, pois, em muitos momentos, materializam produtos que geram fontes de renda para comunidades ou indivíduos (BORGES, 2019). Além disso, muitas vezes são responsáveis por fomentar o convívio social. O grupo paulista de bordadeiras Artesãs da Linha Nove ${ }^{18}$ descreve a importância destas relações e relatam ter encontrado no bordado uma prática de resistência, fortalecimento e de possibilidade de vivenciar situações de solidariedade. No âmbito da cultura é possível observar ainda que "as mulheres se apropriam de suas próprias identidades e as traduzem criativamente, contando suas histórias" (IBID, p. 10).

Aos fatores de mudança elencados por Borges, as proposições de Barbosa Ramos e Prado (2019) acrescentam também aspectos políticos, defendendo que as práticas podem, em certas situações, subverter a função ornamental dos bordados. Algumas vezes aparecem, inclusive, como forma de ativismo:

[...] a partir da reterritorialização dos atos anônimos e domésticos dos trabalhos de agulha que se estendem sobre o espaço público, em que grupos constroem discursos e possíveis diálogos com o público, de forma lúdica e palpável, por meio do craftivismo, forma de ativismo [...] são levantadas uma série de questões que incluem o envolvimento dos sujeitos na ação (BARBOSA RAMOS e PRADO, 2019, PP. 69-74).

Em diálogo, nesta abordagem é pertinente lembrar as proposições do designer e educador austro americano Victor Papanek (1923-1998) em seu livro Design para o mundo real (1971), que argumentava a necessidade da ação social dos designers, não visando apenas motivações econômicas, mas explicitando sua ampla relevância: "o designer deve estar consciente de sua responsabilidade social e moral, pois o design é a ferramenta mais poderosa já dada ao homem para modelar seus produtos, seus ambientes e, por extensão, ele próprio" (PAPANEK, 1971, p. 40, tradução nossa ${ }^{19}$ ). 
Nesse contexto, vale lembrar que o bordado é uma técnica originalmente conectada com práticas artesanais, entretanto bastante utilizada no campo do design, sobre uma diversidade de produtos. A própria técnica, bem como alguns destes artefatos podem ser entendidos como produtos que se localizam entre o artesanato e design. A partir desta compilação de exemplos relativos ao bordado, nossa abordagem seguirá com enfoque nas ações do Coletivo paulistano Linhas de Sampa.

\section{Ações do Coletivo Linhas de Sampa: bordando a resistência}

Como mencionado no tópico anterior, muitos grupos praticam atividades manuais como forma de resistência e cidadania e realizam suas atividades de maneira singular e insurgente, entre eles o Linhas de Sampa. O Coletivo se mantém ativo nas redes sociais por meio de páginas nas plataformas $\mathrm{Fa}^{-}$ cebook e Instagram. Neste artigo, foram usadas estas fontes, somadas a entrevistas com participantes do grupo, bem como acompanhamento de ações de campo, o que resulta numa compilação de dados relevantes ${ }^{20}$.

o Linhas de Sampa iniciou suas atividades graças ao incentivo do grupo Linhas do Horizonte, em razão de um encontro que ocorreu durante o Fórum Social Mundial ${ }^{21}$ do ano de 2018, em Salvador (BA) entre a coordenadora do Coletivo mineiro - a arquiteta e ativista Leda Leonel - com a socióloga e ativista paulistana Lenira Machado. Este convite propunha expandir o projeto para a cidade de São Paulo, com a participação inicial de sete pessoas.

Atualmente, o grupo conta com um total de 77 participantes, número que costuma oscilar, dependendo da participação ativa nas diferentes ações. São pessoas de classe média, com variadas ocupações: jornalistas, professores, servidores públicos, profissionais da área da saúde e também aposentados. Neste artigo, vale ressaltar que o Coletivo será mencionado de maneira grupal, exceto pelo nome de Lenira, que iniciou o projeto. Em outras palavras, não serão informados os nomes dos integrantes, respeitando a proposta que preconiza horizontalidade nas práticas, tal como apontam BRATICH e BRUSH (2011):

\footnotetext{
Numa dimensão mais cotidiana, desenvolvem valores e práticas como orientação, construção de comunidade [...] promovem discussão, compartilhamento de habilidades e relacionamentos entre pessoas com diferentes origens [...], especialmente como uma prática politizada de desenvoltura, conhecimento local e formas organizacionais não hierárquicas (BRATICH e BRUSH, 2011, p. 16, tradução nossa ${ }^{22}$ ).
} 
Na página de Facebook, é possível encontrar o manifesto do Coletivo, do qual destaca-se o trecho a seguir: "Linhas de Sampa é um grupo autônomo de esquerda, suprapartidário, cujas iniciativas independem de partidos, de outros coletivos, de agremiações, de sindicatos etc." (LINHAS DE SAMPA, 2018). Realiza seu trabalho por meio de práticas que podem ser entendidas como "criatividade política". Seus panfletos bordados em tecido, são "bandeiras que se prendem em roupas, sacolas e bolsas e fazem denúncias", contendo palavras e enunciados que defendem causas ligadas aos direitos humanos, sociais e políticos de grupos minoritários, com o objetivo de preservar a democracia e a justiça e problematizar o estado social e político em que se encontra a sociedade.

Seguindo a lógica dos coletivos (BRATICH E BUSH, 2011), o Linhas de Sampa não possui líder, mas sim um colegiado sem hierarquias. O grupo é autofinanciado, não conta com sede própria. Em geral, os integrantes se reúnem mensalmente - normalmente no terceiro domingo de cada mês na Avenida Paulista, em São Paulo (SP). Nestas reuniões acontecem rodas de bordado, quando também são discutidas as pautas e as agendas das ações. As conversas sobre demandas, eventos e manifestações dos quais pretendem participar, são realizadas de maneira horizontal e democrática, por meio de grupos ativos no serviço de mensagens WhatsApp. O Coletivo também organiza oficinas para ensinar técnicas de bordados para comunidades carentes, entre outras intervenções.

Alguns exemplos do trabalho do Linhas de Sampa são apresentados a seguir, e mostram panfletos bordados com frases e desenhos (figuras 6 a 12 , organizadas pelas autoras, de acordo com as temáticas) em favor das populações que vivem em periferias, contra a violência policial, em prol de lutas femininas, em favor da educação, da democracia, da liberdade. Ou ainda, em oposição aos processos imputados contra o ex-presidente Lula ou em defesa dos povos tradicionais e do meio ambiente.

A singularidade se mostra presente nas práticas realizadas pelo Coletivo Linhas de Sampa. É possível perceber que abordam temas coletivos sociais relevantes, porém mitigados por recursos criativos presentes nos desenhos, nas cores, nas texturas e nas palavras. De maneira performativa, com varais e rodas de bordado, o grupo dispara ações insurgentes de afeto "radical". Entendemos o termo "radical", a partir do conceito amplo da palavra, que se qualifica "por um sensível afastamento do que é usual" (FERREIRA, 1999, p. 937). Graças à internet, o grupo também faz reverberar seu trabalho de maneira abrangente, de forma que podem ser percebidos na definição das atividades do Coletivo, sobretudo: "o desejo de ação, de ganhar voz, e marcar posição" (BARBOSA RAMOS e PRADO, 2019, p. 72). 
Fig 6. Bordados contra a violência policial | Fonte: Facebook Coletivo Linhas de Sampa, 2019

Fig 7. Bordados em prol das lutas femininas | Fonte: Facebook Coletivo Linhas de Sampa, 2019 e 2020

Fig 8. Bordados em favor da educação Fonte: Fotos da autora, 2019

Fig 9. Bordados contra a ditadura civil-militar | Fonte: Fotos da autora e Facebook Coletivo Linhas de Sampa, 2019 e 2020

Fig 10. Bordados contra a prisão do ex-presidente Lula | Fonte: Facebook Coletivo Linhas de Sampa, 2018 e 2019

Fig 11. Bordados em defesa do meio ambiente e dos povos tradicionais | Fonte: Facebook Coletivo Linhas de Sampa, 2019

Fig 12. Bordados contra os acidentes ambientais ocorridos em MG | Fonte: Facebook Coletivo Linhas de Sampa, 2019
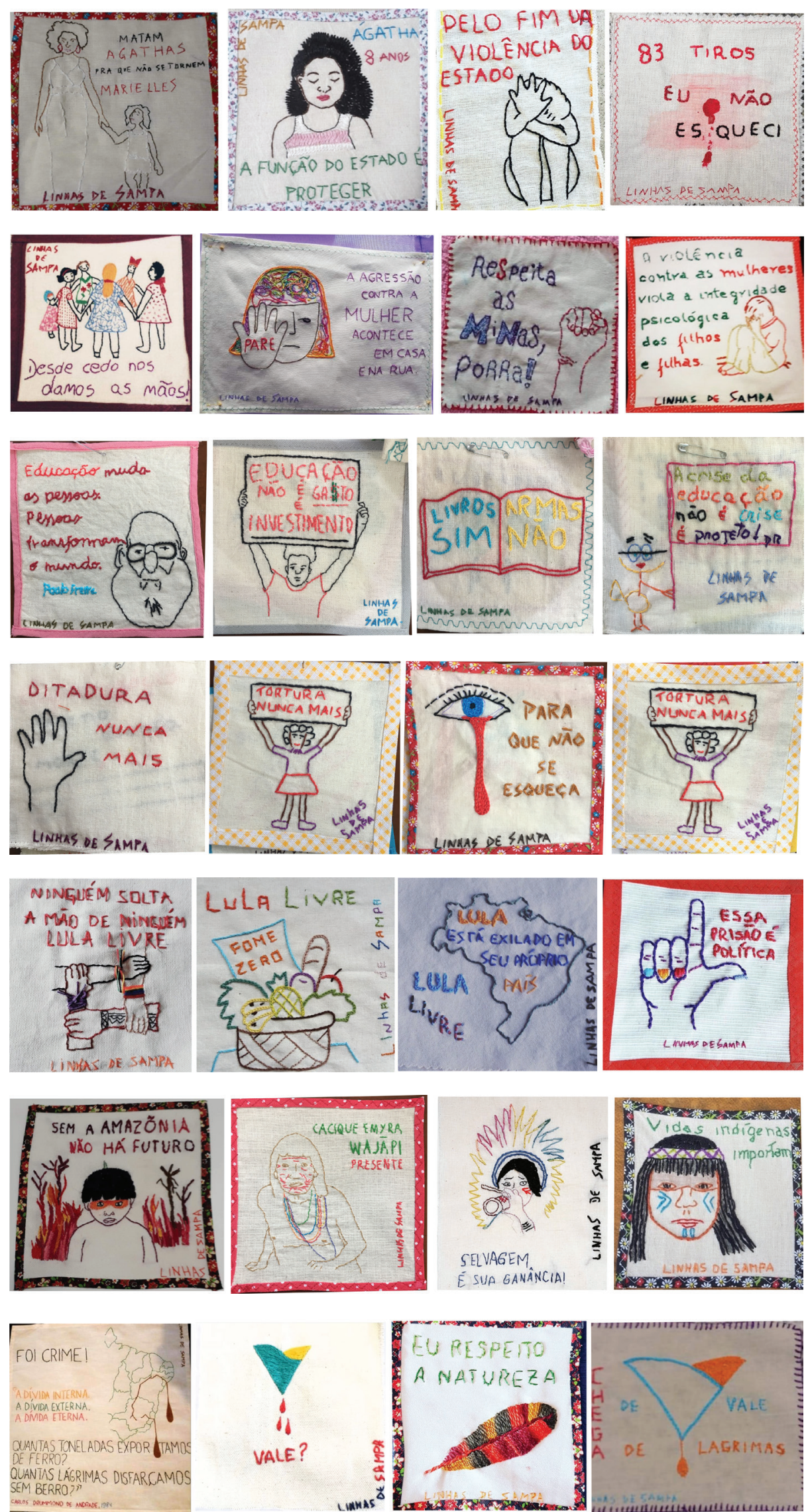
Neste caso, as qualidades do bordado se encontram também, no fato de que a atividade exige poucos recursos para ser realizada (tecido, linha e agulha), o que permite que os panfletos sejam produzidos quase que em tempo simultâneo aos acontecimentos. Pode-se relacionar a baixa complexidade operacional da prática com as proposições de Papanek (1971) para projetos de design socialmente responsáveis:

O design, para ser [...] socialmente responsável, deve ser revolucionário e radical (voltando às raízes) no sentido mais verdadeiro. Ele deve se dedicar ao "princípio de menor esforço" [...] em outras palavras, usando o mínimo de recursos para a diversidade máxima [...] ou, fazendo o máximo com o mínimo (PAPANEK, 1971, p. 140, tradução nossa ${ }^{23}$ ).

\section{Considerações Finais}

Algumas técnicas manuais, artefatos e produtos empregadas do campo no campo do design podem ser entendidas como atos de "resistência", a partir do conceito do latim resistentia, inicialmente compreendido em seu senso comum como "força que se opõe a outra e que não cede a outra; luta em defesa; oposição ou reação à uma forma opressora, força que se opõe ao movimento de um sistema" (FERREIRA, 1999, p. 977).

Por meio da breve revisão histórica conduzida neste artigo, é possível perceber que é recorrente a prática do bordado em universos de lutas predominantemente femininas. Vale comentar a complexidade envolvida nesse tipo de trabalho, que exige boa habilidade física e mental, e paciência para criar os projetos, características consideradas distantes do estereótipo de fragilidade que assombra o universo feminino. O bordado - um gesto emocional, um meio para lidar com sentimentos complexos (PARKER, 2010) - é considerado uma técnica que pode expressar força e integrar atos disruptivos e, até mesmo, subversivos.

É possível verificar conexões entre as práticas de criatividade política realizadas pelo Coletivo Linhas de Sampa e o conceito de ponto subversivo (IBID, 2010) que conduz esse artigo, ao identificar nesta produção de bordados, a transformação de materiais para produzir outros sentidos (SERRAL e MESQUITA, 2019), para além dos ornamentais. 
Em articulação com as reflexões de Borges (2019), pode-se perceber nas ações do Coletivo Linhas de Sampa alguns agentes de mudança e de resistência sociais, ao estabelecer novos vínculos sociais em rodas de bordado, bem como nas outras atividades que o grupo vem praticando. No âmbito cultural, a relevância se dá no enfoque de elementos presentes na cultura nacional, no estímulo das habilidades ligadas a fazeres tradicionais e ainda no fato do grupo lidar com reivindicações do contexto brasileiro. Além disso, os panfletos bordados tornam-se artefatos, situados entre o artesanato e o design, que expressam histórias e símbolos reveladores do que está se passando na subjetividade brasileira, nos últimos anos. Por fim, as proposições de Barbosa Ramos e Prado (2019) contribuem, no sentido de ressaltar que os aspectos políticos dos trabalhos manuais podem ser considerados uma forma potente de ativismo.

1 Design e Resistência: bastidores entre Zuzu Angel e Linhas de Sampa. Iniciada em 2018. Orientadora: Cristiane Mesquita. PPG Design. Universidade Anhembi Morumbi (SP). A pesquisa contextualiza relações entre design e política, por meio dos conceitos de "traje de oposição" e "resistência". Investiga a técnica do bordado e alguns de seus usos em diferentes momentos do cenário político brasileiro, a saber a ditadura civil-militar (1964-1985) e as manifestações em prol das democracias, enfocando o trabalho da designer de moda brasileira Zuzu Angel (19211976), e do Coletivo Linhas de Sampa (2018).

2 A crise imobiliária iniciou com a facilitação no crédito para venda de imóveis, quando as hipotecas eram revendidas para os bancos. A inadimplência das hipotecas fez os valores perderam valor. Bancos faliram, gerando prejuízos ao governo e colapsando o sistema econômico norte-americano (EVANS, 2011).

3 Cerca de $34 \%$ dos países do mundo hoje vivem em regimes autoritários. Disponível em: < https://exame.abril.com.br/mundo/estes-sao-os-regimes-autoritarios-que-ainda-existem-no-mundo/>. Acesso em 18 de abril de 2020.

4 A Primavera Árabe foi impulsionada nas redes sociais, em uma onda de revolta, que se espalhou por outros países do oriente médio, em protestos contra o autoritarismo; na China, reivindicações do movimento democrático questionavam o modelo do governo Comunista; em Hong Kong, o movimento dos guarda-chuvas clamava contra as interferências do Partido Comunista (PINHEIRO-MACHADO, 2019).

5 Alguns exemplos de outros movimentos: Movimento Passe Livre, que defende melhorias no transporte coletivo brasileiro, surgido em 2005. Disponível em:<https://www.mpl.org.br/>. Acesso em 20 de abril de 2020. Mídia Ninja, grupo ativista de comunicações que busca alternativas à imprensa tradicional e atua fortemente desde as manifestações de 2013. Disponível em: < https://midianinja.org/>. Acesso em 20 de abril de 2020.

6 Emissoras como Rede Globo, Sistema Brasileiro de Televisão (SBT), e outras; jornais como Folha de São Paulo, o Globo, entre outros; revistas semanais como Veja, Época, Isto é, dentre outras.

7 ONG feminista criada em 2013, com o objetivo de empoderar muIheres por meio da informação. Disponível em: < https://olga-project. herokuapp.com/sobre/>. Acesso em 21 de abril de 2020.

8 Para mais informações, ver COSTA, Petra. Democracia em vertigem (2018). 9 Luís Inácio Lula da Silva (1945 - ) é um político, ex-sindicalista e ex-metalúrgico brasileiro, e um dos principais fundadores do Partido dos Trabalhadores-PT. Foi o $35^{\circ}$ presidente do Brasil, de 2003 a 2011. Ficou preso de abril de 2018 a novembro de 2019. (PINTO, 2017).

10 Jair Messias Bolsonaro (1955 -), membro do Partido Social Liberal e presidente da República desde 2019 (PINHEIRO-MACHADO, 2019). 
11 Do texto original: "Embroidery has been defined simply as the ornamentation of textiles with decorative stitches. It is an ancient craft which encompasses a wealth of history, and the same stitches are used by embroiderers throughout the world".

12 Ocorrido no Ocidente entre os séculos XV e XVI. Característico pela rejeição aos valores da Idade Média (entre os séculos V e XV) e por demonstrar novamente valorização dos valores da Antiguidade Grega e Romana (BURKE, 2008).

13 Do texto original: "Embroidery, is indoubtely, a cultural practice involving iconography, style and a social function [...] that embroiderers do transform materials to produce sense - whole range of meanings - is invariably entirely overlooked".

14 Período do reinado da Rainha Vitória, no Reino Unido, de junho de 1838 a janeiro de 1901, no século XIX. Os homens dominavam, tanto em espaços públicos, como em privado e as mulheres deviam ser submissas e dedicar-se em exclusivo à manutenção do lar e à educação dos filhos (GARCIA, 2018).

15 A dama à esquerda pergunta a mulher que empurra o carrinho: "Como vai a pequena mulher hoje?", usando o símbolo do gênero feminino (ㅇ) para se referir a ela. A outra mulher responde: "Ela está ficando mais forte e raivosa o tempo todo, obrigada". As flores e o sol são adornados pelo símbolo (ㅇ), na base do bordado está a frase: "De pequenos botões, grandes flores crescem" (tradução nossa).

16 Naif é uma estética que não se enquadra nos moldes acadêmicos, em francês, ingênuo, não se enquadra às regras tradicionais de representação (HODGE AND ANSON, 2006).

17 Para mais informações ver: CINTRA, Fernanda do Nascimento; MESQUITA, Cristiane. Traje de oposição e design de moda: roupa de protesto entre as ruas e a passarela de Zuzu Angel. Revista Educação Gráfica, Vol. 23, nº. 03, 2019, Pp. 278-297. Disponível em: <http://www. educacaografica.inf.br/artigos/traje-de-oposicao-e-design-de-moda-roupa-de-protesto-entre-as-ruas-e-a-passarela-de-zuzu-angel-oppositional-dress-and-fashion-design-protest-clothing-between-streets-and-zuzu-angels-catwa>; e ANDRADE, Priscila. Zuzu Angel: o poder da moda contra a opressão. Anais do $2^{\circ}$ Colóquio de Moda, Salvador, Bahia. 04 a 07 de outubro de 2006. Disponível em: <http://www.coloquiomoda. com.br/coloquio2017/anais/anais/edicoes/2-Coloquio-de-Moda_2006/ artigos/94.pdf>.

18 As bordadeiras da Linha Nove são moradoras da favela da Linha, favela do Nove, duas das maiores favelas de São Paulo (BORGES, 2019). 19 Do texto original: "[...] the designer must be conscious of his social and moral responsibility. For design is the most powerful tool yet given man with which to shape his products, his environments, and, by extension, himself".

20 Não foram encontradas publicações científicas a respeito do grupo. A entrevista foi concedida por integrantes do Coletivo Linhas de Sampa à autora em 13 de agosto de 2019 e 14 de abril de 2020. As ações acompanhadas foram: Tsunami pela Educação, Avenida Paulista (SP), 13 de agosto de 2019; e movimento Resiste Venezuela, Armazém do Campo (SP), dia 27 de fevereiro de 2020.

21 Encontro anual articulado por movimentos sociais para discutir pautas contra o neoliberalismo e as desigualdades sociais (RELATÓRIO FSM, 2018).

22 Do texto original: "On a more everyday level, craftivists develop values and practices like mentorship, comunity building [...] promotes discussion, skill-sharing, and relationships among people with different backgrounds [...] especially as a politicized practice of resourcefulness, local knowledge, and nonhierarchical organization forms".

23 Do texto original "Design, if it is to be [...] socially responsive, must be revolutionary and radical (going back to the roots) in the truest sense. It must dedicate itself to nature's 'principle of least effort', in other words, minimum inventory for maximum diversity [...] or, doing the most with the least". 


\section{Referências}

ABRANTES, Talita. Ao menos 10 cidades terão atos em memória de Marielle Franco. Exame, São Paulo, 15 de março de 2018. Versão eletrônica. Disponível em: < https://exame. abril.com.br/brasil/ao-menos-10-estados-terao-atos-em-memoria-de-marielle-franco/>. Acesso em: 23 de abril de 2020.

ANDRADE, Bianca. “Gente estranha tirou a vida do meu pai”, diz Aikyry Wajãpi. Amazônia Real, Amapá, 10 de setembro de 2019. Disponível em: < https://amazoniareal.com.br/gente-estranha-tirou-a-vida-do-meu-pai-diz-aikyry-wajapi/>. Acesso em: 23 de abril de 2020.

BALLOUSSIER, Anna Virgínia. Lula Livre domina ato por Luiz Marinho em SP. Folha de São Paulo. São Paulo, 16 de agosto de 2018. Versão eletrônica. Disponível em: < https://www1. folha.uol.com.br/poder/2018/08/lula-livre-domina-ato-por-luiz-marinho-em-sp.shtml>. Acesso em: 23 de abril de 2020.

BARBOSA RAMOS, Regina; PRADO, Gilbertto. Uma bomba lançada: Reflexões sobre motivos e efeitos do Yarnbombing. DATJournal, V4, N2, 2019b, p. 69-76. Disponível em: < https://doi. org/10.29147/dat.v4i2.131>. Acesso em: 01 de abril de 2020.

BARBOSA, Vanessa. Inferno na floresta: o que sabemos sobre os incêndios na Amazônia. São Paulo. Exame, 22 de agosto de 2019. Versão eletrônica. Disponível em: < https:// exame.abril.com.br/brasil/inferno-na-floresta-o-que-sabemos-sobre-os-incendios-na-amazonia/>. Acesso em: 21 de abril de 2020.

BOECKEL, Cristina. Protesto no Rio cobra punição à Vale por desastre ambiental em Mariana. G1, Rio de Janeiro, 16 de novembro de 2015. Versão eletrônica Disponível em: < http://g1.globo.com/rio-de-janeiro/noticia/2015/11/protesto-no-rio-cobra-punicao-vale-por-desastre-ambiental-em-mariana.html>. Acesso em: 20 de abril de 2020.

BORGES, Adélia. Entremeadas. São Paulo: Sesc Vila Mariana, 2019. Catálogo da exposição, 15 out.-09 fev., 2019. Sesc São Paulo.

BRATICH, Jack Z., BRUSH, Heidi M. Fabricating Activism: Craftwork, Popular Culture, Gender. In Utopian Studies Vol. 22, No. 2, Special Issue Craftivism, 2011.

CARNEIRO, Julia Dias; GRAGNANI, Juliana; ROSSI, Amanda. \#EleNão: A manifestação histórica liderada por mulheres no Brasil vista por quatro ângulos. BBC News Brasil em São Paulo, Rio de Janeiro e Londres, 30 de setembro de 2018. Versão eletrônica. Disponível em: < https://www.bbc.com/portuguese/brasil-45700013>. Acesso em: 21 de abril de 2020.

EL PAÍS. A cronologia da investigação que levou Lula à prisão. Madri, 07 de abril de 2018. Versão eletrônica. Disponível em: <https://brasil.elpais.com/brasil/2018/04/05/politica/1522917041_563602.html>. Acesso em: 24 de abril de 2020.

EVANS, Trevor. Cinco explicações para a crise financeira internacional. In Revista Tempo do Mundo. IPEA. Instituto de pesquisa de economia aplicada. V3 n1. abril de 2011. Disponível em: <http://repositorio.ipea.gov.br/bitstream/11058/6248/1/RTM_v3_n1_Cinco.pdf>. Acesso em: março de 2020.

FELICE, Massimo; PEREIRA, Eliete, ROZA, Erick (orgs). Net-Ativismo: Redes digitais e novas práticas de participação. Campinas: Papirus, 2017.

FELLET, João; SOUZA, Felipe. Brumadinho é maior acidente de trabalho já registrado no Brasil. BBC News em São Paulo, 29 de janeiro de 2019. Versão eletrônica. Disponível em: <https://www.bbc.com/portuguese/brasil-47012091>. Acesso em: 20 de abril de 2020. 
FERNANDES JR, Florestan. O Tubo vai fechar. Brasil 247. São Paulo Disponível em: https:// www.brasil247.com/pt/colunistas/florestanfernandes/385320/O-tubo-vai-fechar.htm. Acesso em: 12 de fevereiro de 2020.

FERREIRA, Aurélio Buarque de Holanda. Novo Aurélio Século XXI: O Dicionário da Língua Portuguesa. Rio de Janeiro: Nova Fronteira, 1999.

FLORESTI. Felipe. Manifestações de 'junho de 2013' completam cinco anos: o que mudou?. Galileu, Rio de Janeiro, 20 de junho de 2018. Versão eletrônica. Disponível em: < https://revistagalileu.globo.com/Revista/noticia/2018/06/manifestacoes-de-junho-de-2013-completam-cinco-anos-o-que-mudou.html>. Acesso em: 24 de abril de 2020.

G1. Cidades brasileiras de todo o país têm atos em defesa da educação e contra a reforma da Previdência. São Paulo, 13 de agosto de 2019. Versão eletrônica. Disponível em: < https:// g1.globo.com/educacao/noticia/2019/08/13/cidades-brasileiras-tem-atos-em-defesa-da-educacao.ghtml>. Acesso em: 22 de abril de 2020.

G1. Índios protestam contra a morte de Paulino Guajajara e denunciam falta de ação das autoridades. São Luís, Maranhão, 04 de novembro de 2019. Disponível em: < https://g1. globo.com/ma/maranhao/noticia/2019/11/04/indios-protestam-a-morte-de-paulino-guajajara-e-denunciam-a-falta-de-acao-das-autoridades.ghtml>. Acesso em: 21 de abril de 2020. G1. Mãe é presa pela PM durante protesto contra violência policial. São Paulo, 02 de julho de 2018. Versão eletrônica. Disponível em: <https://g1.globo.com/sp/sao-paulo/noti$\mathrm{cia} /$ mae-e-presa-pela-pm-durante-protesto-contra-violencia-policial.ghtml>. Acesso em: 20 de abril de 2020 .

G1. Manifestantes fazem ato em SP contra morte de músico baleado pelo Exército no Rio: '80 tiros em uma família negra'. São Paulo, 14 de abril de 2019. Disponível em: < https://g1.globo.com/sp/sao-paulo/noticia/2019/04/14/manifestantes-fazem-ato-em-sp-contra-morte-de-musico-baleado-pelo-exercito-no-rio-80-tiros-em-uma-familia-negra. ghtml>. Acesso em: 21 de abril de 2020.

G1. Rio tem protestos após morte de Ágatha Félix: 'Que a Justiça seja feita', diz tia. Rio de Janeiro, 23 de setembro de 2019. Versão eletrônica. Disponível em: < https://g1.globo.com/ $\mathrm{rj} /$ rio-de-janeiro/noticia/2019/09/23/rio-tem-manifestacao-apos-morte-da-menina-agatha-felix.ghtml>. Acesso em: 22 de abril de 2020.

GANDERTON, Lucinda. Embroidery. New York. DK Publishing. 2015.

GARCIA, Carla Cristina. Breve História do Feminismo. São Paulo: Claridade, 2015.

HODGE, Nicola; ANSON, Libby. A-Z of art. The world greatest and most popular artists and their works. Londres: Carlton, 2006.

LINHAS DE SAMPA, Coletivo. Bordando por Justiça! Facebook do Coletivo Linhas de Sampa. São Paulo. 26 de abril de 2018. Disponível em: < https://m.facebook.com/notes/linhas-de-sampa/linhas-de-sampa-bordando-por-justi\%C3\%A7a/791440711066517/>. Acesso em: 01 de abril de 2020.

LINHAS DE SAMPA, Coletivo. Entrevista concedida por COLETIVO LINHAS DE SAMPA. Entrevistadora Fernanda do Nascimento Cintra. São Paulo, 2020. Arquivos .mp3 (19 minutos e 12 segundos) e (2 minutos e 40 segundos).

LINHAS DE SAMPA, Coletivo. Fotos Facebook do Coletivo Linhas de Sampa. São Paulo. Disponível em: <https://m.facebook.com/pg/linhasdesampa/photos/>. Acesso em: 5 de abril de 2020. 
LINHAS DO HORIZONTE, Coletivo. Nossa História - Linhas do Horizonte - Bordando a resistência. Facebook do Coletivo Linhas do Horizonte. São Paulo. 26 de dezembro de 2017. Disponível em: < https://m.facebook.com/notes/linhas-do-horizonte/nossa hist\%3\%B3ria/1830583390585769/>. Acesso em: 12 de abril de 2020.

LLOYD, Trevor. Um sexo em luta. In. Um sexo em luta: 0 governo e as sufragistas. Agitação social e Emigração. São Paulo: Editora Abril, 1968.

MALERONKA, Wanda. Fazer roupa virou moda: um figurino de ocupação da mulher (São Paulo 1920-1950). São Paulo: Senac, 2007.

MELO, Cristina Teixeira Vieira; VAZ Paulo Roberto Givaldi. E a corrupção coube em 20 centavos. In. Galaxia. n.39 . São Paulo, 2018. Disponível em: < http://www.scielo.br/pdf/gal/ n39/1519-311X-gal-39-0023.pdf>. Acesso em: 18 de abril de 2020.

MORAES, Luís Edmundo. História Contemporânea: Da Revolução Francesa à Primeira Guerra Mundial. São Paulo: Editora Contexto, 2017.

MUSEUM OF LONDON. Suffrage banner. Museum of London Prints. Disponível em: <https://www.museumoflondonprints.com/image/177698/suffrage-banner-of-hammersmith-wspu-20th-century>. Acesso em: 5 de dezembro de 2019.

NINJA. Para fortalecer a luta anti racista, campanha promove 21 dias de ativismo no mês de março. Mídia Ninja, São Paulo, 09 de março de 2019. Versão eletrônica. Disponível em: <https://midianinja.org/news/para-fortalecer-a-luta-anti-racista-campanha-promove-21-dias-de-ativismo-no-mes-de-marco/>. Acesso em: 21 de abril de 2020.

PAPANEK, Victor. Design for the real world: human ecology and social change. Chicago: Academy Chicago Publishers, 1985.

PARKER, Rozsika. The Subversive Stitch: Embroidery and the Making of the femininity. Londres. IB Taurus, 2010.

PINHEIRO-MACHADO, Rosana. Amanhã vai ser maior: o que aconteceu com o Brasil e as possíveis rotas de fuga para a crise atual. São Paulo, 2019.

PINHEIRO-MACHADO, Rosana; SCALCO, Lucia. Da Esperança ao Ódio: Pobreza e Política do lulismo ao bolsonarismo. In. Cadernos IHU Idéias. No. 278. Vol. 16. 2018. Disponível em: https://www.academia.edu/37751341/Da_Esperan\%C3\%A7a_ao_\%C3\%93dio_Pobreza_e Pol\%C3\%ADtica_do_lulismo_ao_bolsonarismo. Acesso em: 20 de abril de 2020.

ROSSI, Marina. As mulheres brasileiras dizem basta. El País Brasil, São Paulo, 04 de novembro de 2015. Versão eletrônica. Disponível em: <https://brasil.elpais.com/brasil/2015/11/03/politica/1446573312_949111.html>. Acesso em: 20 de abril de 2020.

RUFATTO, Luiz. 0 “Fora, Temer" Brasil afora. El País Brasil, São Paulo, 08 de setembro de 2016. Versão Eletrônica. Disponível em: < https://brasil.elpais.com/brasil/2016/09/07/ opinion/1473260994_023470.html> . Acesso em: 21 de abril de 2020.

SERRAL, Isabelle; MESQUITA, Cristiane. O corpo encontra a roupa: Design de Moda entre normatização e utopia. DATJournal, V4, N3, 2019, p. 52-75. Disponível em: < https://doi. org/10.2 9147/dat.v4i3.147>. Acesso em: 15 de abril de 2020.

SOUZA, Jessé. A radiografia do golpe: entenda como e por que você foi enganado. Rio de Janeiro. Editora Leya, 2016.

VALLI, Virgínia. Eu, Zuzu Angel, procuro meu filho. Rio de Janeiro: Record, 1987.

WATSON, Fiona. Bolsonaro: 100 dias de guerra contra os povos indígenas. São Paulo, El País, 16 de abril de 2019. Versão Eletrônica. Disponível em: < https://brasil.elpais.com/brasil/2019/04/11/politica/1554971346_439815.html>. Acesso em: 20 de abril de 2020.

Recebido: 19 de março de 2020. Aprovado: 05 de maio de 2020. 